\title{
Dual RNA-seq transcriptional analysis of wheat roots colonized by Azospirillum brasilense reveals up-regulation of nutrient acquisition and cell cycle genes
}

Doumit Camilios-Neto ${ }^{1,4}$, Paloma Bonato ${ }^{1}$, Roseli Wassem², Michelle Z Tadra-Sfeir ${ }^{1}$, Liziane CC Brusamarello-Santos ${ }^{1}$, Glaucio Valdameri ${ }^{1}$, Lucélia Donatti ${ }^{3}$, Helisson Faoro ${ }^{1}$, Vinicius A Weiss ${ }^{1}$, Leda S Chubatsu' ${ }^{1}$, Fábio O Pedrosa ${ }^{1}$ and Emanuel M Souza ${ }^{* *}$

\begin{abstract}
Background: The rapid growth of the world's population demands an increase in food production that no longer can be reached by increasing amounts of nitrogenous fertilizers. Plant growth promoting bacteria (PGPB) might be an alternative to increase nitrogenous use efficiency (NUE) in important crops such wheat. Azospirillum brasilense is one of the most promising PGPB and wheat roots colonized by A. brasilense is a good model to investigate the molecular basis of plant-PGPB interaction including improvement in plant-NUE promoted by PGPB.

Results: We performed a dual RNA-Seq transcriptional profiling of wheat roots colonized by A. brasilense strain FP2. cDNA libraries from biological replicates of colonized and non-inoculated wheat roots were sequenced and mapped to wheat and A. brasilense reference sequences. The unmapped reads were assembled de novo. Overall, we identified 23,215 wheat expressed ESTs and 702 A. brasilense expressed transcripts. Bacterial colonization caused changes in the expression of 776 wheat ESTs belonging to various functional categories, ranging from transport activity to biological regulation as well as defense mechanism, production of phytohormones and phytochemicals. In addition, genes encoding proteins related to bacterial chemotaxi, biofilm formation and nitrogen fixation were highly expressed in the sub-set of $A$. brasilense expressed genes.

Conclusions: PGPB colonization enhanced the expression of plant genes related to nutrient up-take, nitrogen assimilation, DNA replication and regulation of cell division, which is consistent with a higher proportion of colonized root cells in the S-phase. Our data support the use of PGPB as an alternative to improve nutrient acquisition in important crops such as wheat, enhancing plant productivity and sustainability.
\end{abstract}

Keywords: RNA-seq, Transcriptional analysis, Wheat, Triticum aestivum, Azospirilum brasilense, PGPB, Cell cycle and nitrogen fixation

\footnotetext{
* Correspondence: souzaem@ufpr.br

'Department of Biochemistry and Molecular Biology, Universidade Federal do Paraná, Curitiba, PR 81531-990, Brazil

Full list of author information is available at the end of the article
} 


\section{Background}

The global human population is projected to be 9 billion by 2050. To meet this rapid growth of the world's population the predicted demand for food production must increase 1.7 fold by 2050 [1-3]. On the other hand, such increase in food production must be obtained with reduced agricultural inputs, in particular those related to nitrogenous $(\mathrm{N})$ fertilizer, for long term sustainability of food production. Reduction in $\mathrm{N}$ fertilizer use will bring at least two benefits: i) reduced emissions of $\mathrm{CO}_{2}$ and gaseous $\mathrm{N}$ oxides from agricultural processes and ii) decrease of the food production costs, since up to $50 \%$ of the operational cost for crop productions arises from $\mathrm{N}$ fertilizers [1,3]. In addition, for the last 40 years crop production increased by 2.4 fold mostly promoted by a 7.4 fold increase in mineral $\mathrm{N}$ fertilizers application, which means that the $\mathrm{N}$ use efficiency (NUE) has declined 3.1 fold in that time $[3,4]$.

An alternative to improve NUE is to use plant growthpromoting bacteria (PGPB), since these bacteria are able to increase root-system development and improve acquisition of nutrient including $\mathrm{N}[2,3]$. Azospirilla is one of the most promising PGPB genera. In Latin America, hundreds of thousands of hectares have been inoculated with Azospirillum-based commercial inoculants, increasing grain yields of economically important crops such maize and wheat $[5,6]$.

Wheat (Triticum aestivum) is one of the oldest and widespread crop species. With a production of approximately 630 million tons per year, this crop feeds more than $35 \%$ of the world's population $[7,8]$. Significant worldwide efforts of wheat-breeding programs, supported by modern biotechnology, have been applied to increase grain yield, nutritional content, as well as salinity-, droughtand biotic-tolerance [1].

Studies of plant-bacterial interactions (mostly phytopathogens) have been taking advantage from high-throughput techniques and also from the constant improvement of genome sequencing and annotation of both bacteria and plants $[9,10]$. However, there is a lack in the application of these recently established techniques in the area of plantPGPB interaction [6]. Furthermore, although it is well documented that PGPB, in particular A. brasilense, can increase plant productivity in several important crops, the mechanism of the plant-bacterial interaction is not entirely understood $[6,11,12]$.

Here we performed a dual (plant and bacterium) RNAseq transcriptional profiling of colonized wheat roots, motivated by the idea that a better understanding of both wheat and $A$. brasilense gene expression might bring insights into: i) the molecular mechanisms of host response; ii) the bacterial colonization strategies; and iii) how to improve plant productivity.

\section{Results}

Improved growth of wheat seedlings colonized by Azospirillum brasilense

A model of plant-bacterial interaction was set up under axenic conditions. Surface sterilized wheat seeds were germinated on plates of agar/water and transferred to glass tubes containing $25 \mathrm{~mL}$ of salt solution (Hoagland's medium without carbon or nitrogen sources). Wheat seedlings were incubated at $26^{\circ} \mathrm{C}$ for 24 hours with a light cycle of 14 hours and then inoculated with $0.25 \mathrm{~mL}$ of bacterial suspension containing $1.5 \times 10^{7} \mathrm{CFU}$ per milliliter. Controls were carried out with non-inoculated wheat seedlings.

Bacterial counts showed that three days after inoculation root colonization reached $3.2 \times 10^{7} \mathrm{CFU}$ per gram of fresh tissue (Figure 1), but no bacteria were recovered from surface sterilized roots indicating that the $A$. brasilense strain FP2 is an epiphytic colonizer. Root mass of colonized plants increased up to $30 \%$ when compared with non-inoculated plants and the total mass of colonized plants increased by $25 \%$ compared with noninoculated plants (Figure 2a). Wheat root size was also enhanced in colonized plants (Figure 2b). In addition, we have analyzed colonized and non-inoculated wheat roots by cell flow cytometry: the number of cells with higher content of DNA increase up to $40 \%$ in inoculated roots, indicating a higher proportion of cells in the S-phase (Figure 2c).

Bacterial adhesion and biofilm formation on wheat roots were visualized by scanning electron microscopy (Figure 3). Electron micrographs showed abundant adhering material, which might be composed of a matrix of extracellular polysaccharides (Figure $3 \mathrm{~b}$ ). A. brasilense anchored on wheat roots by extracellular-polysaccharide rich material was reported previously [13]. In addition, A. brasilense adhered to wheat roots visualized by transmission electron microscopy contained a high amount of granules of poly-hydroxy-alkanoate (PHA) (Figure 3d).

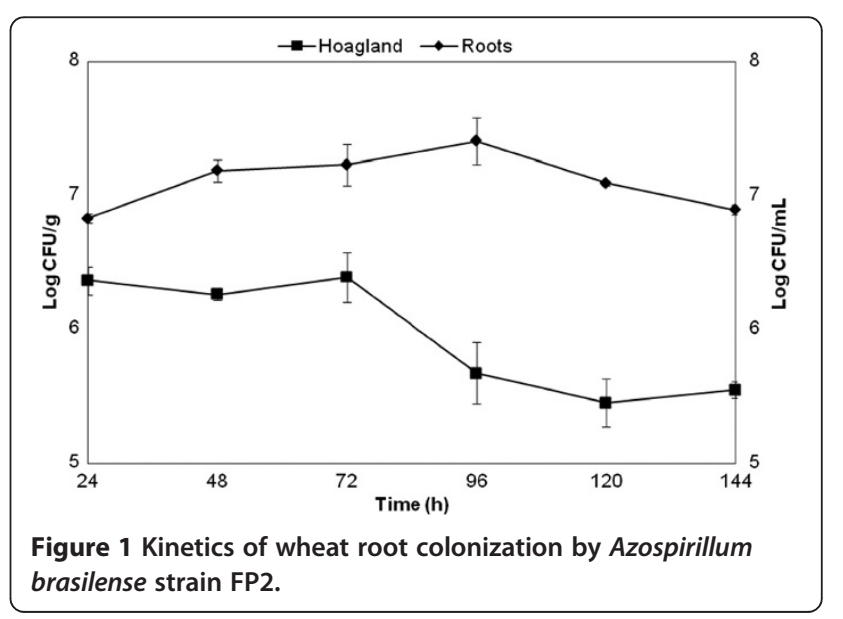



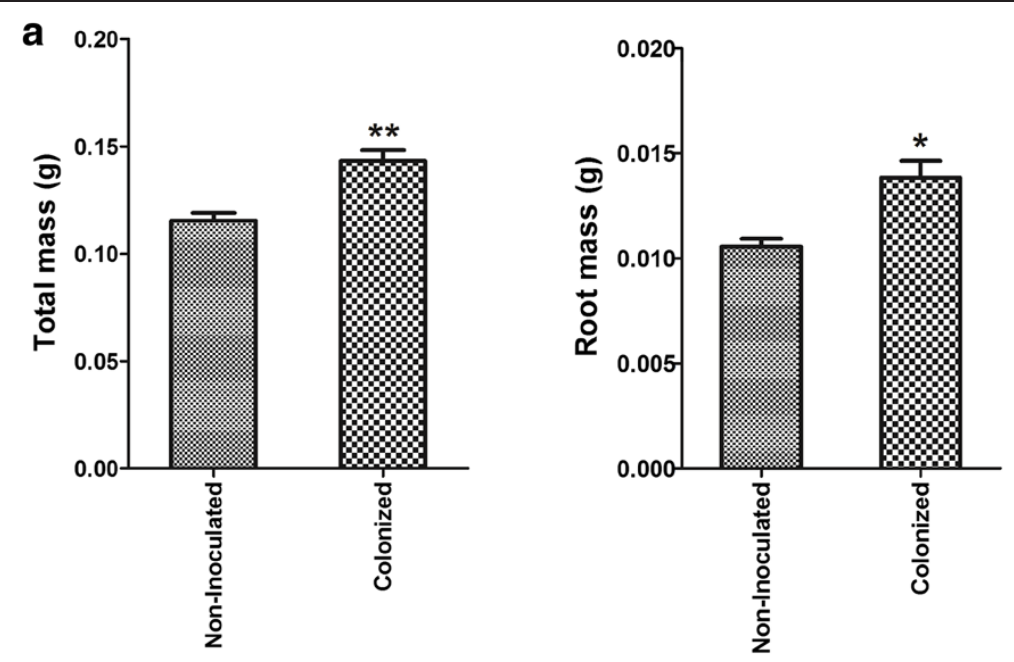

b
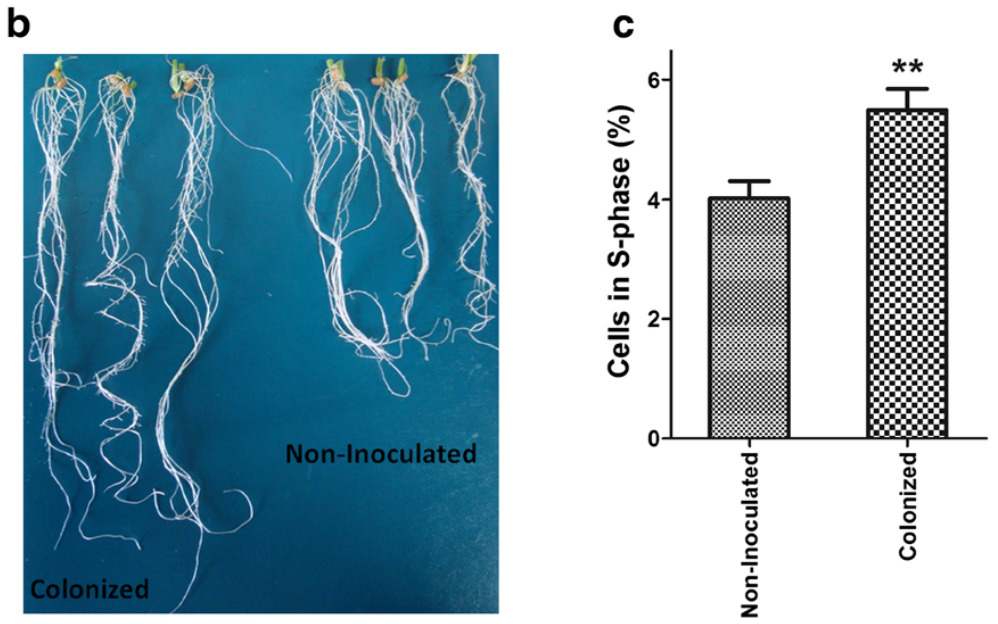

Figure 2 Improvement of wheat seedlings growth inoculated with Azospirillum brasilense strain FP2. (a) Total plant mass and root mass eight days after colonization; (b) improvement of wheat root size in colonized plants after twenty days of colonization; (c) measurement of the

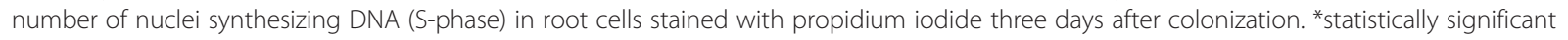
t-test $(p$-value $<0.05 \%)$ and ${ }^{* *}$ statistically significant t-test ( $p$-value $\left.<0.01 \%\right)$.

PHAs are important during periods of carbon and energy starvation, and in $A$. brasilense the accumulation of these reserve materials was reported to support chemotaxis, motility and cell multiplication [14].

\section{RNA-seq transcriptional profiling}

The RNA-seq transcriptional analysis was carried out in two independent samples (biological replicates) of each treatment (colonized or non-inoculated), yielding a total of 4 sequencing libraries of seedling roots, which were designated CWR1 and CWR2 libraries (colonized roots) and N-IWR1 and N-IWR2 (non-inoculated roots) (Additional file 1: Figure S1). Each sample was made up of roots of 10 seedlings ( $100 \mathrm{mg})$. Two sequencing runs of each CWR and N-IWR cDNA libraries generated 306 million $50 \mathrm{bp}$ reads yielding more than 15 gigabase of sequenced data. The total of sequenced reads was first mapped to the T. aestivum ribosomal RNA to clean-up the sequence data from wheat rRNA (Figure 4). Approximately 9 gigabase of rRNA-free sequence data was then mapped to three reference datasets: 1) UniGene-EST of T. aestivum; 2) MicroRNAs-databank of T. aestivum; and 3) A. brasilense FP2 draft genome. A total of 23,215 expressed sequences from wheat roots and 228 expressed sequences from $A$. brasilense, both with 3-fold or higher coverage, were then quantitatively analyzed.

\section{RNA-seq transcriptional profiling: mapping strategy}

After the ribosomal RNA removal, the analyses of the wheat roots transcriptome profiling involved 3 mainsteps (Figure 4): 1) sequential mapping of reads to different reference datasets (UniGene-EST of $T$. aestivum, MicroRNAs-databank of $T$. aestivum and A. brasilense genome sequence); 2) de novo assembly of unmapped 


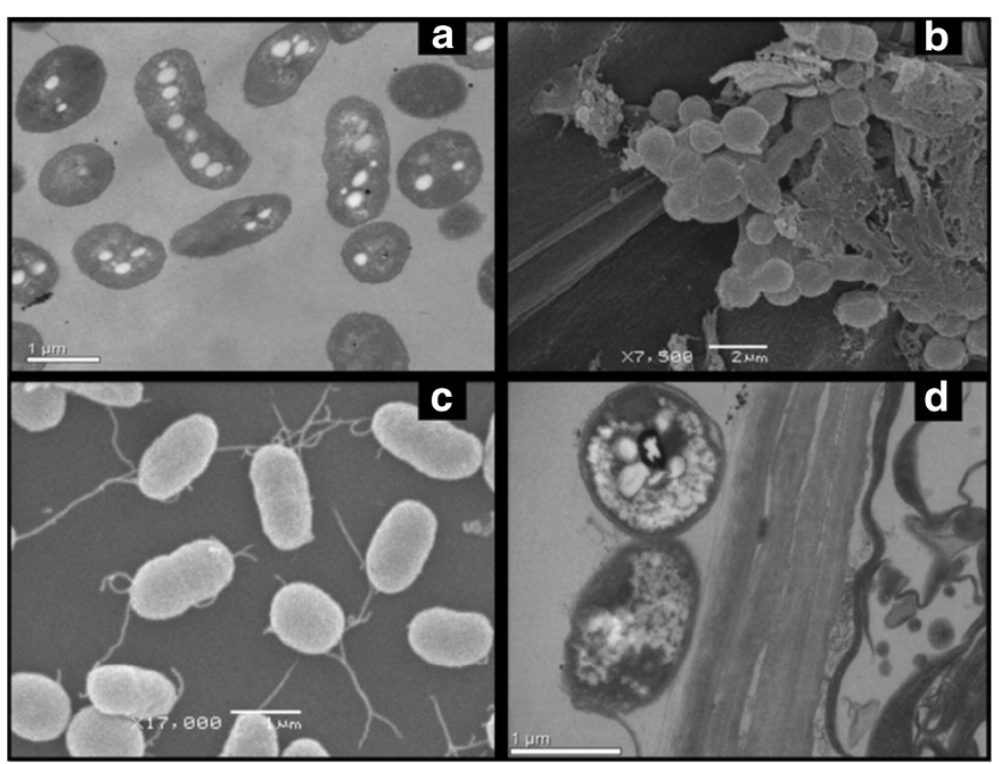

Figure 3 Electron micrographs of Azospirillum brasilense strain FP2 on wheat roots and electron micrographs of FP2 in liquid culture. (a) transmission electron micrographs of FP2 grown in liquid culture; (b) scanning electron micrographs of biofilm structure on wheat roots; (c) scanning electron micrographs of FP2 growing in liquid culture; (d) transmission electron micrograph of FP2 adhered to wheat roots.

reads; and 3) mapping of unmapped reads to de novo assembled ESTs. Using this strategy, we were able to improve the number of mapped reads by 2.5 -fold (data not shown). The removal of reads mapping to $T$. aestivum ribosomal RNA sequences from the CWR and N-IWR libraries (Figure 4) was necessary to avoid expression bias, since in a first mapping trial using as reference UniGeneEST a high number of ESTs/rRNA chimeras was found (data not shown). The rRNA-free sequences of CWR and N-IWR (CWR-UnM 1 and N-IWR-UnM 1, respectively) were then mapped to T. aestivum UniGene-ESTs data sequence. A total of 16,645 ESTs of wheat was expressed, 12,366 in the CWR libraries and 16,231 in N-IWR libraries (Additional file 2: Table S1A, S1B and Additional file 3: Table S2).

The UniGene-unmapped sequences (CWR-UnM 2 and N-IWR-UnM 2) were then mapped to the microRNAsdataset of $T$. aestivum. Among the 85 described wheat microRNAs [15] fifteen were expressed, 13 in CWR- and 12 in N-IWR-libraries (Additional file 4: Table S3). The microRNAs-unmapped sequences (CWR-UnM 3 and NIWR-UnM 3) were subsequently mapped to the $A$. brasilense genome sequence strain Sp245 [16] and to a draft genome of the FP2 strain (unpublished data). Two hundred and twenty eight genes of the A. brasilense FP2 strain were identified in the CWR libraries with $3 \times$ or higher coverage and none in the N-IWR libraries. Furthermore, when a less stringent coverage cut-off $(1 \times)$ was applied, $702 \mathrm{~A}$. brasilense transcripts were identified in the CWR libraries and no expressed ORF was found in the N-IWR libraries (Figure 4).
Finally, the unmapped reads, named CWR-UnM 4 and N-IWR-UnM 4, which represent reads that did not align to any of the reference sequence datasets, were used to assemble the transcripts de novo. A total of 7,288 contigs were assembled and used as reference to map the reads of the CWR-UnM 4 and N-IWR-UnM 4 libraries (Figure 4). Of the 7,288 assembled contigs, 6,570 had enough mapped reads ( $3 \times$ or higher coverage) to be considered expressed; 6,505 in the CWR libraries and 6,551 in the N-IWR libraries (Figure 4).

\section{RNA-seq biological variability}

Biological variability was checked by Pearson correlation coefficients comparing DEseq-normalized expression values within the biological replicates. Correlation coefficients for CWR libraries were 0.93, 0.99, 0.99 and 0.96 (UniGene, microRNAs, A. brasilense, de novo assembled transcripts, respectively), whereas biological replicates of N-IWR libraries had correlation coefficients of 0.92 , 0.97 and 0.81 (UniGene, microRNAs and de novo assembled transcripts, respectively). Correlation coefficient for A. brasilense-mapped reads was not calculated for N-IWR libraries since no expressed ORF was found in these libraries. Overall, data reproducibility in this study was high and, except for N-IWR mapped to de novo assembled transcripts, all pair correlation coefficients were $\geq 0.92$.

\section{Comparison of Triticum aestivum RNA-seq profiles: CWR vs N-IWR}

Gene expression levels in the CWR (inoculated with A. brasilense) libraries are expressed as fold-differences 


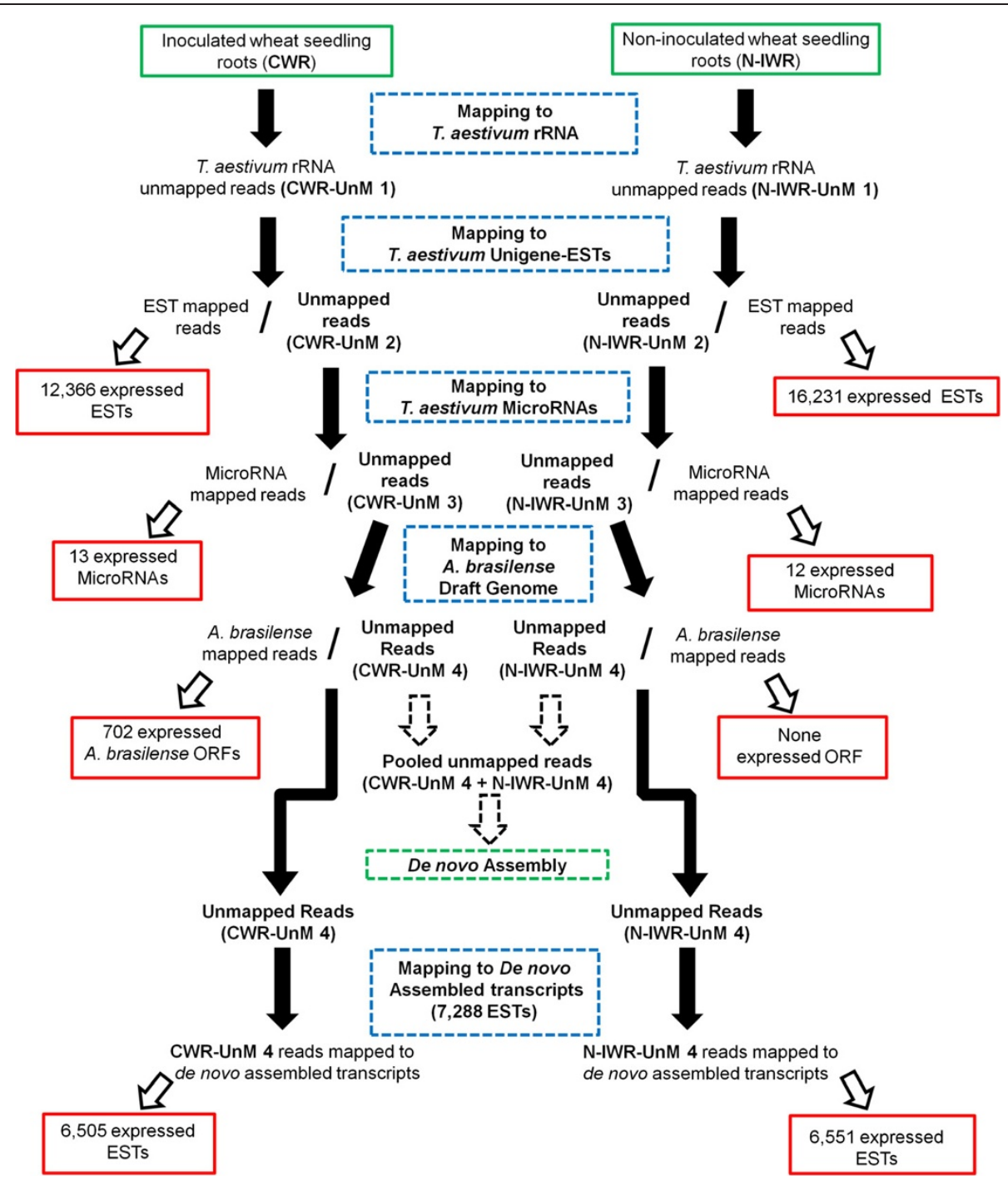

Figure 4 Mapping strategy.

in relation to the expression levels in the N-IWR (noninoculated) libraries. In the following sections, when we attribute effects on gene expression to $A$. brasilense colonization, we are comparing CWR libraries with N-IWR libraries.

Within the 23,215 expressed-ESTs (16,645 UniGenemapped and 6,570 from the assembled transcripts) A. brasilense colonization caused changes in the expression of 776 ESTs (fold-change $\geq 2$ and $p$-value $<0.05$ ), hereafter named as regulated-ESTs. Of these, 313 ESTs were upregulated and 463 ESTs were down-regulated (Additional file 5: Table S4).

To gain insight into the putative processes involved in the plant-bacterial cross-talk a gene ontology (GO) analysis of the three GO categories - biological processes (BP), molecular functions (MF) and cellular components (CC) - was carried out (Figure 5). To determine whether any of the categories were overrepresented in the group of regulated-ESTs we compared the percentage of each GO category in the sub-set of regulated-ESTs to the percentage of same GO category in the sub-set of expressed-ESTs, and values higher than 1.5 -fold were considered overrepresented in the subset of regulatedESTs. The overrepresented categories in the subset of up-regulated ESTs included: 1) transport activity and enzyme regulator activity (MF); 2) biological regulation and death (BP); and 3) macromolecular complex and extracellular region (CC). While in the downregulated sub-set these categories comprised: 1) transcription factor activity (MF); 2) biological regulation (BP); 3) macromolecular complex and extracellular region (CC) (Figure 5 and Additional file 6: Table S5A, S5B). 

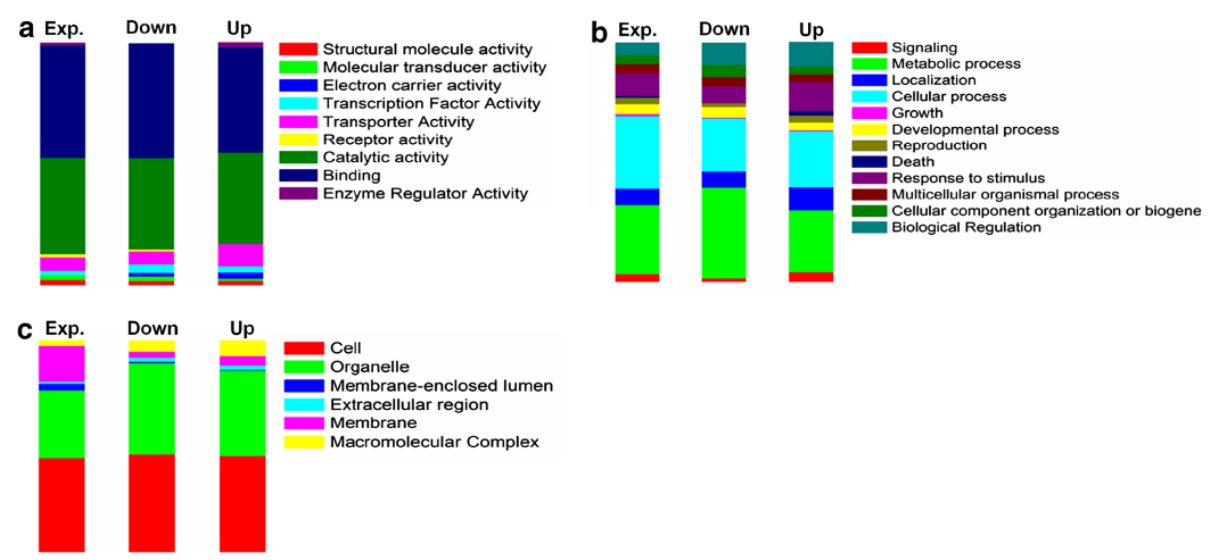

Figure $\mathbf{5}$ Gene ontology analysis. Expressed and differentially expressed wheat genes were classified in the three main gene ontology categories: (a) Molecular Functions; (b) Biological Processes; and (c) Cellular Components. Exp: expressed; Down: down-regulated in colonized roots; Up: up-regulated in colonized roots.

mRNA levels by quantitative reverse transcription PCR (RT-qPCR)

Quantitative reverse transcription PCR was used to confirm the differential expression of ten selected genes from T. aestivum (Additional file 7: Figure S2) and four from A. brasilense (Table 1). In all these genes, there were a very good correlation between RNA-seq and RT-qPCR (Pearson coefficient correlation between RNA-seq and RTqPCR to $T$. aestivum $>0.97$, $p$-value $<0.0001)$. T. aestivum gene expression was normalized according to transcript levels of $p p 2 a c 5, u b c c E 2$ and a beta-3-tubulin transcript and $A$. brasilense genes according to rpo $C$ transcript levels. The selected genes comprised both sub-sets of regulated ESTs (i.e., up- and down-regulated ESTs).

\section{Identification of differentially expressed microRNA of} Triticum aestivum inoculated with Azospirillum brasilense Fifteen wheat microRNAs were found in the RNASeq data, and one of them, tae-MIR444, was up-regulated in the colonized roots (8.6-fold, p-value 0.019) (Additional file 4: Table S3). MIR444 and its predicted target, MADS box transcriptional factors, are conserved in monocots. MADS box transcriptional factors play key roles in controlling floral organ development in cereals during vernalization

Table 1 RT-qPCR validation: $A$. brasilense on wheat roots vs. free living $A$. brasilense $e^{a}$

\begin{tabular}{ll}
\hline Genes & RT-qPCR log2Fold-change \\
\hline nifH & $4.6 \pm 0.16^{*}$ \\
sbpA & $7.5 \pm 0.23^{* * *}$ \\
narL-like & $6.4 \pm 0.01^{* * *}$ \\
trpB & $-2.3 \pm 0.16^{* *}$ \\
\hline
\end{tabular}

${ }^{\mathrm{a}} A$. brasilense grown microaerophilic on NFbHP-lactate containing $20 \mathrm{mM} \mathrm{NH}_{4} \mathrm{Cl}$. Significant differences in the RT-qPCR $\left({ }^{*} p<0.05,{ }^{* *} p<0.01\right.$, and $\left.{ }^{* * *} p<0.001\right)$ were determined using one-tailed t-test. (extended exposure to low temperature that induces plants from temperate regions to flower) $[17,18]$. One other possible target for MIR444 is an homolog of A. thaliana regulatory factor ANR1, which is a MADS box transcriptional factor that promotes lateral roots elongation in response to nitrate supply $[19,20]$. Seventeen ESTs encoding MADS box transcriptional factors were expressed in the wheat roots, but no significant change in expression was noted when we compared CWR to N-IWR libraries (Additional file 8: Table S6). Further investigation is required to determine the possible role of MIR444 up-regulation in colonized roots.

\section{Azospirillum brasilense expressed transcripts in wheat roots}

Of the 702 expressed genes of $A$. brasilense those related to bacterial adhesion, adaptation processes and nitrogen fixation were the most recurrent (Additional file 9: Table S7). We identified several genes encoding proteins related to the initial steps of plant-bacterial interaction (chemotaxis, adhesion and biofilm formation). The $s b p A$ gene, which encodes an acidic $A$. brasilense protein induced by root exudates [21], was highly expressed in the CWR-libraries. RT-qPCR analyses confirmed expression of $s b p A$ in A. brasilense colonizing wheat roots (Additional file 9: Table S7 and Table 1). The protein SbpA is required for chemotaxis towards sugars (e.g., $\mathrm{D}$-galactose, $\mathrm{L}$-arabinose and D-fucose) and is involved in the uptake of D-galactose [22]. The transcriptional regulator GbpR and the $A B C$ sugar transporters GguA and GguB were also highly expressed in the CWR-libraries. Additionally, genes encoding: monosaccharides transporters, and proteins related to polysaccharides, exo-polysaccharides and lipopolysaccharides biosynthesis and transport were also highly expressed in the CWR-libraries (Additional file 9: Table S7). Moreover, three genes of calcium-binding proteins (two of 
them being hemolysin-type), which have been associated with Rhizobium adhesion on host roots [23], were expressed in CWR-libraries. Taken together these results suggest that the time point of the colonization picked to perform the RNA-seq experiments (i.e., three days of colonization) corresponds to the initial steps of plantbacterial interaction, when chemotaxis, adhesion and biofilm formation are prominent processes.

Interestingly, a narL-like gene was highly expressed in CWR-libraries, a result confirmed by RT-qPCR analyses (Additional file 9: Table S7 and Table 1). NarX/NarL is a classical two-component system of membrane sensor protein $(\mathrm{NarX})$ and DNA-binding regulator (NarL) that regulates the respiratory membrane-bound nitrate reductases in E.coli and P. aeruginosa [24,25]. In addition, among the expressed genes we found seven ORFs involved in production of poly- $\beta$-hydroxy-alkanoates (PHAs) (PHB polymerases, poly(3-hydroxyalkanoate) synthetase and phasins). This result is consistent with the finding of high amounts of intracellular PHAs in A. brasilense cells colonizing wheat root surface (Figure 3d). Finally, expression of $A$. brasilense superoxide dismutase (SodB) (Additional file 9: Table S7) indicates activation of oxidative stress protection systems of $A$. brasilense against plant-defense oxidative burst.

A. brasilense is able to convert atmospheric nitrogen into ammonium through the action of the nitrogenase complex under appropriate conditions (e.g., microaerobically and low nitrogen levels) [26] and it may transfer fixed nitrogen to the associated plant. The relative high expression of nitrogenase complex genes (nifHDK operon), which was also confirmed by RT-qPCR analyses (Table 1), suggest that $A$. brasilense adhered to wheat roots is fixing nitrogen. Expression of nitrogenase complex on wheat roots has been shown using nifH:lac $Z$ fusion $[27,28]$.

\section{Differentially expressed wheat genes associated to plant- microbe interaction}

First, we focused our analysis on the screening of the host response usually found at some stage of plantmicrobe interaction. The wheat ESTs encoding host response proteins were grouped into three sets: 1) defense mechanism; 2) hormone imbalances and 3) secretion of phytochemicals.

\section{Defense mechanism}

We looked at the wide variety of inducible defense mechanisms (e.g., oxidative burst, production of antimicrobial compounds and expression of defense-related genes [29,30]) usually triggered upon microbe recognition. Hundreds of defense-related ESTs (R-genes-encode resistance-proteins e.g., kinases with leucine rich repeat receptors (LRR-kinases), endoglucanases, disease resistance proteins, etc.) were found among the expressed ESTs (data not shown); twenty-eight of those had changes in their expression in response to A. brasilense colonization (Additional file 10: Table S8). Changes in expression of R-genes were found in both sub-sets of down-regulated (12 ESTs) and up-regulated ESTs (16 ESTs). In addition, ten heat shock proteins (Hsp), which play roles in plant response defense and are also required to fold LRR-receptors in a signal competent state $[31,32]$ were found in sub-sets of up-regulated ESTs (Additional file 10: Table S8).

\section{Hormone imbalances in colonized plants}

The phytohormones auxins and ethylene have been intensely studied in plant growth and development. Three ESTs encoding auxin-induced proteins changed their expression in response to $A$. brasilense colonization (Additional file 10: Table S8). The first was a transcriptional factor ETTIN/ARF3, which mediates auxin dependent flower and fruit development by binding on auxin receptor (AuxRec) (3.6-fold, down-regulated). An aldo-keto-reductase auxin-induced was also downregulated (2-fold) while a calmodulin-dependent auxininduced protein SAUR (small auxin up RNA), whose response is mediated by calcium, was up-regulated (4.3fold). In addition, three calmodulin-like proteins were down-regulated by $A$. brasilense colonization (Additional file 10: Table S8). Additional investigations are required, including gene expression of aerial parts of wheat, to bring insights into the pattern of auxin-related gene expression in response to $A$. brasilense colonization.

$A$. brasilense colonization promoted an interesting decrease of expression of $A C O$, which encodes for ACC oxidase (3.1-fold) (Additional file 10: Table S8). ACC oxidase catalyzes the conversion of 1-aminocyclopropane1-carboxylate $(\mathrm{ACC})$ to ethylene. Although ethylene production regulation is most related to ACC synthase expression, ACC oxidase transcription also contributes to regulation of ethylene production [33]. This result suggests a decreased amount of ethylene production in inoculated wheat roots. Thus, $A$. brasilense colonization might suppress the inhibition of root cell elongation promoted by ethylene, reflected in the improvement of root systems of colonized plants.

\section{Secretion of phytochemicals}

Three ESTs encoding enzymes related to flavonoids biosynthesis showed expression decreased in response to A. brasilense colonization: flavonol 3-sulfotransferase and two anthocyanidin -o-glucosyltransferases (Additional file 10: Table S8). Flavonol 3-sulfotransferase catalyzes flavonoid sulfation, and flavonoid sulfates are supposed to be involved in detoxification of active hydroxyl groups and in sequestering of sulfate groups of plants growing under saline conditions. Interestingly, anthocyanin biosynthesis is 
activated by nitrogen deficiency, while nitrogen compounds (e.g., fertilizers) repress the flavonoid biosynthesis $[34,35]$, raising the possibility of improvement of nitrogen nutrition of the colonized wheat roots.

\section{Wheat response to Azospirillum brasilense colonization}

A. brasilense colonization caused changes in the expression of 776 ESTs ranging from transporters, heat shock proteins, helicases, resistance-proteins (R-genes), to cell cycle control.

Close to five hundred ESTs encoding transporters were expressed by wheat roots; among these, 9 were upregulated and 3 down-regulated (Additional file 11: Table S9). In addition, 559 more EST encoding proteins, which were grouped in transport activity by GO analysis, were expressed in wheat roots (10 up- and 11 down-regulated) (Additional file 12: Table S10). Interestingly, genes encoding a nitrate efflux transmembrane transporter (homolog of $A$. thaliana NAXT) and an oligopeptide transporter (PTR2) were 4.2- and 2.6-fold, respectively, up-regulated, whilst another twenty three nitrate transporters showed no significant change in expression (Additional file 11: Table S9). However, we did not find any significant change in nitrogen content (including nitrate) in the hydroponic medium 3 days after wheat roots inoculation (data not shown). On the other hand, two ESTs encoding a cytosolic form of glutamine synthetase (GS1) were up-regulated (3.1- and 2.3-fold) (Additional file 11: Table S9). GS activity composes the major route for inorganic $\mathrm{N}$ incorporation into organic molecules [3]. GS1 expression was also shown to be up-regulated in sugar cane seedlings colonized by the PGPB Gluconacetobacter diazotrophicus and Herbaspirillum rubrisubalbicans [36].

Twenty-two ESTs encoding proteins related to cell cycle regulation and improvement of root growth showed changes in their expression responding to $A$. brasilense colonization, 16 in the sub-set of up-regulated and 8 in the down-regulated ESTs (Additional file 13: Table S11). The higher number of up-regulated ESTs of this class agreed with the flow cytometry results (Figure 2c) that showed an increased proportion of cells in the S-phase, which indicate higher rates of DNA replication in colonized wheat roots.

\section{Discussion}

\section{Simultaneous RNA-Seq analysis of wheat roots and} Azospirillum brasilense

To our knowledge, this is the first report of a dual RNASeq transcriptional analysis of plant-PGPB interaction (simultaneous analysis of changes in expression of both host and bacteria). There are only few studies with the application of high-throughput techniques (e.g., RNASeq) in plant-PGPB interactions [6], including those focused either on the host or the PGPB. On the other hand, investigation of host-pathogen interactions by dual RNA-Seq (HeLa cell and vaccinia virus [37]; bone marrow-derived dendritic cells from Mus musculus and the pathogen fungus Candida albicans [38] and Oryza sativa and Magnaporthe oryzae (blast fungus) [10]) has become feasible and expected to become the gold standard in the studies of host-microbe interactions [9]. Further dual RNA-Seq quantitative studies of plant-PGPB interaction should be undertaken in order to improve knowledge of the molecular basis of plant benefits by PGPB.

Although the common wheat (Triticum aestivum) is one of the most important food crops in the world, the complete assembly of its genome sequence is not available. Large genome (16 Gb), high amount of repetitive sequences $(\approx 90 \%)$ and hexaploid nature make the complete assembling of wheat genome a very hard task to be accomplished. Luckily, RNA-Seq transcriptional profiling is a quite practical alternative to assess the functional genome of non-model organisms with no defined genome reference.

Several wheat transcriptional studies have successfully applied RNA-Seq analyses to investigate wheat transcriptomes applying two main strategies: 1) assembling of sequenced reads into contigs (e.g., homoeolog-specific assembly of wheat transcriptome [39], optimization of de novo assembly of wheat transcriptome [40], assembly of sequence reads from three bread wheat varieties to identify SNPs candidates [41], assembly of sequence reads into contigs to investigate the transcription factor GPC (grain protein content) during monocarpic senescence [42], and assembly of transcripts to investigate polyploidization events in common wheat [43]); and 2) mapping the sequenced reads to a reference of wheat ESTs or to a genome of a correlated organism such as rice (Oryza sativa) (e.g., transcriptome of starchy endosperm of the developing wheat seeds, at different times of aleurone layer development [44], transcriptome analysis of the developing starchy endosperm [45], mapping of sequence reads into the unigene sequences from two lines of wheat to identify SNPs [46] and mRNA tag analysis to investigate cellular and metabolic responses of wheat seedlings triggered by $\mathrm{H}_{2} \mathrm{O}_{2}$ [47]).

Here, we used a mixed strategy, by mapping the reads to wheat-ESTs and assembling of unmapped sequence reads. This strategy allowed for an improvement in the number of quantitatively analyzed genes.

\section{A possible role of NarX/NarL-like operon on Azospirillum- wheat root adhesion}

The NarX/NarL operon regulates the respiratory membranebound nitrate reductases in E.coli and P. aeruginosa [24,25]. Nitrate binds to the $\mathrm{P}$ box element (a highly conserved 
nitrate recognition region of NarX) altering NarX conformation, allowing its auto-phosphorylation and subsequent phosphorylation of NarL, which in turn binds to specific DNA target sites resulting in activation or repression of target operon transcription [24,25]. In E. coli expression of the narXnarL operon is activated by Fnr proteins under limitation of oxygen and by NarL in the presence of nitrate [24]. Interestingly, in $P$. aeuruginosa NarX/NarL plays an essential role in the biofilm through the activation of the motility regulon that controls the biofilm dispersion [25]. The NarL-like protein of $A$. brasilense expressed during colonization may play a similar role in adhesion to the root surface.

\section{Triticum aestivum expression profile modulated by Azospirillum brasilense colonization Nitrate transporters}

Plants respond to nitrate, which is the major source of mineral nitrogen for higher plants, improving its up-take and metabolism. The most prominent effect of nitrate supply is the stimulation of lateral root formation [20]. Genes encoding a nitrate efflux transmembrane transporter $(N A X T)$ and an oligopeptide transporter of the NRT1(PTR) family (PTR2) were up-regulated in colonized roots. Nitrate efflux was reported in response to stress-generated $\mathrm{pH}$ acidification in A. thaliana growing in hydroponic medium [48]. Nitrate efflux was also reported as an early signaling mechanism in tobacco plants as a response defense against crytogein, a proteinaceous elicitor from a virulent tobacco pathogen (Phytophthora cryptogea) [49]. Additional investigations are required to determine a possible role of nitrate efflux transmembrane transporter up-regulation in colonized roots.

\section{Phytochemicals and phytohormones}

It is well known that secretion of phytochemicals is a critical step in plant-microbe interaction [50-52]. For example, plant root exudates containing flavonoids are recognized by Rhizobium and play a critical role in the legume-rhizobium symbiosis [51,52]. In addition, plant hormones (phytohormones) play important roles in response to biotic stress, e.g., bacterial colonization. Besides their significant role in response to biotic stress, phytohormones also play essential roles in the regulation of plant growth and development [30,53,54]. Abiotic and biotic stresses challenge plant tissues triggering ethylene production, which promotes, among other effects, inhibition of plant root cell elongation [33]. The ACC oxidase (ACO) expression was down-regulated in colonized roots. Since $A C O$ transcription contributes to regulation of ethylene production, decreasing $A C O$ expression reflects in lower amount of ethylene in wheat roots, avoiding ethylene inhibition effects in root elongation of colonized wheat seedlings [33]. ACC oxidase expression also can be used as an indicator of osmotic stress (drought or saline stresses). Pepper plants (Capsicum annuum L.) inoculated with PGPB (Bacillus sp. and Arthrobacter sp.) presented a significant decrease in $A C O$ expression when compared with the non-inoculated plants under osmotic stress promoted by PEG (polyethylene glycol) treatment. The decrease of $A C O$ expression might contribute to the relief of osmotic stress by these PGPB [55]. A decrease in endogenous ethylene levels also plays a role in bacterialinduced salinity tolerance [56].

Plants growing under saline conditions produce flavonoid sulfates, which might be implicated in detoxification of active hydroxyl groups and in the sequestering of sulfates groups [57]. Even though wheat seedlings were not under a typical saline stress condition, the gene that encodes a flavonol 3-sulfotransferase, which catalyzes flavonoid sulfation, was down-regulated in colonized roots, suggesting that colonized plants are more resistant to saline stress. Taken together, these results suggest that $A$. brasilense colonization besides promoting enhancement of the root system may play a role in plant stress tolerance, an effect previously observed in other studies (Figure 6) [56,58-64].

\section{Improvement of nutrient up-take in inoculated wheat roots}

In addition to several reports of increases in root biomass promoted by Azospirillum inoculation $[6,11,12]$, here we present evidence that $A$. brasilense colonization improve

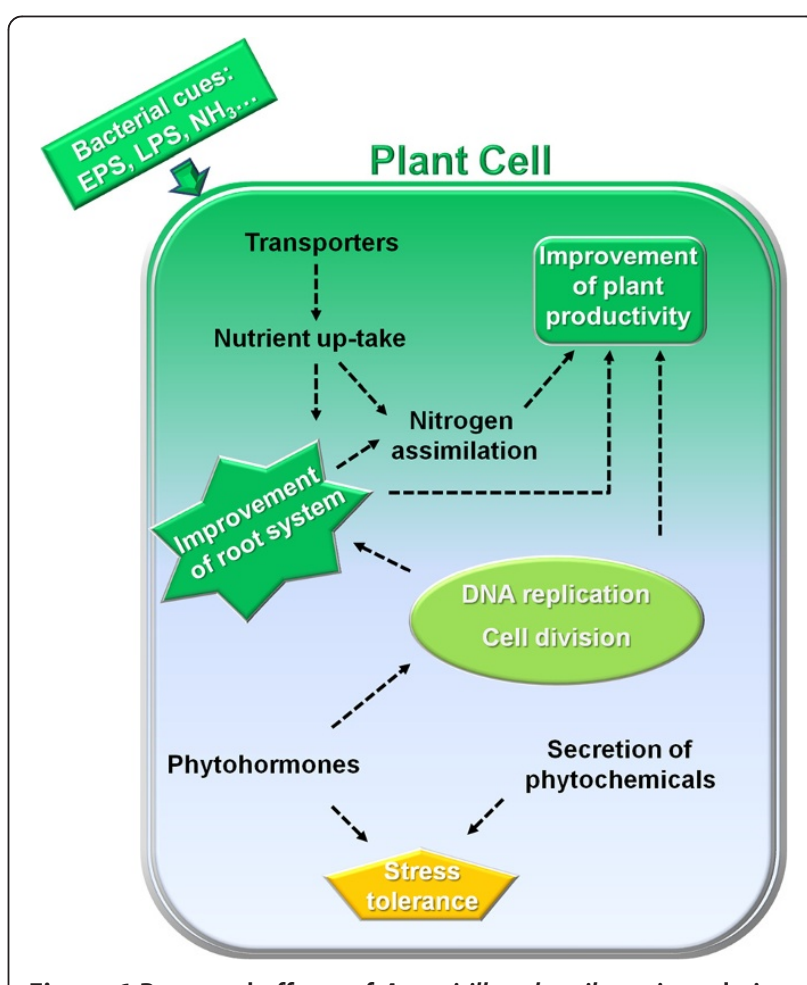

Figure 6 Proposed effects of Azospirillum brasilense inoculation. 
nutrient acquisition by not only increasing the root surface area, but also by regulating the expression of nutrient transporters (Figure 6). Supporting this hypothesis, our results suggest: 1) enhancement of root surface area followed by increased DNA synthesis in root cells and upregulation of ESTs encoding cell cycle regulators; 2) repression of $A C O$ expression that might reflect in lower ethylene production; and 3) up-regulation of transporters ranging from metal- to oligopeptides-transporters.

Additionally, EST encoding proteins related to anthocyanin biosynthesis, which is usually repressed by increased amount of nitrogen content [34,35], were down-regulated in CWR-libraries suggesting higher amount of nitrogen content in the colonized plants. Finally, the up-regulation of wheat glutamine synthetase and of $A$. brasilense nitrogenase strongly suggests that the PGPB colonization improves nitrogen nutrition of wheat plants.

\section{Conclusions}

Simultaneous RNA-Seq of plant roots colonized by $A$. brasilense showed a remarkable change in expression of plant genes involved in transport activity, reflected in a direct effect on the up-take of nutrients, such as nitrogen. Additionally, genes of categories related to DNA replication and cell division were also responsive to the presence of the bacteria. These changes in gene expression are likely correlated with improvement in growth of wheat seedling colonized by $A$. brasilense under axenic conditions. The results reinforce the use of PGPB as an alternative to improve nutrient acquisition in important crops such as wheat. Finally, genetic manipulation of the differentially expressed wheat genes may lead to the development of new cultivars with improved productivity traits.

\section{Methods}

\section{Plant growth and bacterial colonization}

T. aestivum (CD-104 cv.) seeds were surface-sterilized by washing with ethanol $70 \%$ for $0.5 \mathrm{~min}$, followed by shaking $(120 \mathrm{rpm})$ for $5 \mathrm{~min}$ with acid hypochlorite, washing 3-times with ultrapure sterilized water and $4 \mathrm{~h}$ incubation with ultrapure sterilized water at room temperature. The seeds were then incubated in a rotary shaker $(120 \mathrm{rpm})$ for $5 \mathrm{~min}$ with acid hypochlorite [0.5\% (v/v) $\mathrm{NaOCl}, 0.18 \%(\mathrm{v} / \mathrm{v})$ concentrated $\mathrm{HCl}, 0.01 \%$ (v/v)

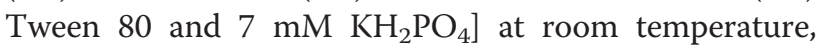
washed 3-times with ultrapure sterilized water, followed by a 5 min incubation with $\mathrm{H}_{2} \mathrm{O}_{2} 35 \%$ (v/v). Finally, the seeds were washed 4-times with ultrapure sterilized water and then germinated in water agar plates at $30^{\circ} \mathrm{C}$ for $12 \mathrm{~h}$ under darkness. Germinated seedlings were transferred to sterile glass tubes containing $25 \mathrm{~mL}$ Hoagland's nutrient solution [65] (two seedlings per tube) and cultivated at $26^{\circ} \mathrm{C}$ under $14 \mathrm{~h}$ light $/ 10 \mathrm{~h}$ darkness for $24 \mathrm{~h}$. Each tube was then inoculated with $0.25 \mathrm{~mL}$ of $A$. brasilense FP2 suspension. Bacterial suspension was prepared by growing A. brasilense FP2 in a $60-\mathrm{mL}$ flask containing $10 \mathrm{~mL}$ NFbHP-lactate medium [66] supplemented with $20 \mathrm{mM}$ of $\mathrm{NH}_{4} \mathrm{Cl}$ at $30^{\circ} \mathrm{C}$ and $120 \mathrm{rpm}$ in an orbital shaker to an optical density $(600 \mathrm{~nm})$ of 1.0 . The culture was then centrifuged and the pellet was re-suspended in $100 \mathrm{~mL}$ Hoagland's nutrient solution (without nitrogen or carbon) to approximately $1.5 \times 10^{7} \mathrm{CFU} / \mathrm{mL}$. The inoculated seedlings were incubated for 3 days at $26^{\circ} \mathrm{C}$ under $14 \mathrm{~h}$ light/ 10 h darkness. Non-inoculated control seedlings were cultivated exactly as described except that $0.25 \mathrm{~mL}$ of sterile Hoagland's nutrient solution was added.

\section{Azospirillum brasilense cells count}

Colonized $T$. aestivum seedling roots were weighed, macerated in sterile saline solution, diluted, and plated on NFbHP-lactate agar containing $20 \mathrm{mM} \mathrm{NH}_{4} \mathrm{Cl}$. Bacterial populations were expressed as CFU/g of fresh roots. Bacterial counts were also performed with surfacesterilized roots ( $1 \mathrm{~min}$ in $70 \%$ ethanol, followed by $1 \mathrm{~min}$ in $1 \%$ chloramine $\mathrm{T}$ (Sigma) and rinsed 3 times with sterile water) in order to check whether the $A$.brasilense FP2 strain was able of endophytic colonization. Bacterial cells were also counted in the Hoaglands solution bathing the roots and expressed as CFU/mL.

\section{Nuclei isolation and flow cytometry}

The relative DNA content was analysed essentially as described by [67]. Shortly, T. aestivum roots were collected three-days after inoculation and sliced with a single-edge razor blade in a glass petri dish containing nuclei isolation buffer ( $45 \mathrm{mM} \mathrm{MgCl} 2,20 \mathrm{mM}$ MOPS, $30 \mathrm{mM}$ sodium citrate, $0.1 \%$ Triton X-100, pH 7.0) [67]. Nuclei (in $1.5 \mathrm{~mL}$ buffer) were passed through a filter of pore size $40 \mu \mathrm{m}$, stained with $50 \mu \mathrm{g} / \mathrm{mL}$ propidium iodide (PI) and analyzed on a FACS Calibur flow cytometer (Becton, Dickinson and Company, USA) with CellQuest software. Side scatter versus forward scatter dot plots were used to locate and gate nuclear populations by particle size. The FL2-A channel was used for detection of PI fluorescence (DNA content). The DNA content of at least 5000 nuclei were analyzed in each sample.

\section{Transmission electron microscopy and scanning electron microscopy}

T. aestivum roots were fixed with Karnovsky's fixative [68], post-fixed with $2 \% \mathrm{OsO}_{4}$ in $0.1 \mathrm{M}$ cacodylic acid buffer ( $\mathrm{pH}$ 7.2) for $1 \mathrm{~h}$ and embedded in Epon 812 [69]. After contrasting with $2 \%$ uranyl acetate [70] and lead citrate [71], samples were examined with a JEOL-JEM 1200 EX II transmission electron microscope. For scanning electron microscopy, $T$. aestivum roots were fixed with Karnovsky's fixative [68], washed in $0.1 \mathrm{M}$ cacodylic acid buffer ( $\mathrm{pH} 7.2)$ and dehydrated in ethanol. Critical- 
point dryness was obtained with a Bal-Tec CPD - 030, the samples were coated with gold using a Balzers SCD 030 sputter coater and examined with a JEOL-JSM 6360 LV scanning electron microscope.

\section{RNA-seq profiling experiment}

The RNA-seq transcriptional analysis was carried out with two biological replicates of each treatment (colonized and non-inoculated $T$. aestivum roots). Each replicate consisted of roots of ten $T$. aestivum seedlings (five tubes with two seedlings per tube) (Additional file 1: Figure S1). $T$. aestivum roots were washed twice with sterilized water, cut, mixed with RNAlater (Applied Biosystems, Carlsbad, $\mathrm{CA}$ ) and stored at $-80^{\circ} \mathrm{C}$. Total RNA extraction, rRNA depletion, library construction and cDNA sequencing on a Life Technologies' SOLiD $4^{\circ}$ platform were performed according to the manufacturer's instructions. The libraries were mapped to $T$. aestivum and $A$. brasilense sequence references using CLC Genomics Workbench 4.8, with a tolerance of 2 mismatches, and minimum length fraction of 0.9 to A. brasilense and 0.8 to T. aestivum and minimum similarity fraction of 0.8 for both. Only uniquely mapped reads were considered in our analysis. The unmapped reads were de novo assembled using CLC Genomics Workbench 4.8 [accession number, EMBL: E-MTAB-2301]. DEseq package was used to estimate differential gene expression, performing a negative binomial distribution and a shrinkage estimator for the distribution's variance and size-factor normalization [72]. The differentially expressed genes were considered to be significant at $p$-value $<0.05$ and absolute fold-change $\geq 2$ fold. Gene ontology analysis was performed by Blast2go software [73].

\section{Analysis of gene expression by RT-qPCR}

RT-qPCR was carried out with two independent biological replicates (other than those used for RNA-seq experiments) of colonized and non-inoculated $T$. aestivum roots (Additional file 1: Figure S1). Two micrograms of extracted RNA was used to synthesize cDNA with a high-capacity cDNA reverse transcription kit (Applied Biosystems, Carlsbad, CA). Relative expression levels were estimated as described [74]. T. aestivum target gene expression was normalized to that of $p p 2 a c 5, u b c c E 2$ and a beta-3-tubulin using geNorm 3.4 software [75] and A. brasilense target genes to that of rpoC. All samples were run in triplicate and significant differences were determined using one-tailed $\mathrm{t}$-test.

\section{Additional files}

Additional file 1: Figure S1. RNA-Seq and RT-qPCR experiments design. CWR: colonized wheat roots; N-IWR: non-inoculated wheat roots; each biological replicate was compound by five tubes with two seedlings per tube.

Additional file 2: Table S1A. RNA-seq: mapping results. Table S1B. RNA-seq: expressed and differentially expressed genes. ${ }^{a} 3 \times$ or higher coverage; ${ }^{b} 1 \times$ or higher coverage; ${ }^{c}$ Not determined.

Additional file 3: Table S2. Triticum aestivum Expressed ESTs. ${ }^{a}$ Foldchange in red indicates down-regulation in colonized wheat roots (CWR); (+) ND not expressed in the N-IWR libraries; (-) ND not expressed in the CWR libraries.

Additional file 4: Table S3. Triticum aestivum expressed micro-RNAs. a Fold-change in red indicates lower level of expression in colonized wheat roots (CWR); ${ }^{b}$ Not considered as expressed micro-RNA.

Additional file 5: Table S4. Differentially expressed Triticum aestivum-ESTs. aFold-change in red indicates down-regulation in colonized wheat roots (CWR); (+) ND not expressed in the N-IWR libraries; (-) ND not expressed in the CWR libraries.

Additional file 6: Table S5A. Overrepresented GO categories of up-regulated Triticum aestivum-ESTs in colonized roots. Table S5B. Overrepresented GO categories of down-regulated Triticum aestivum-ESTs

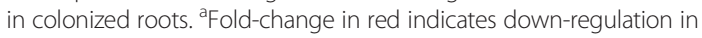
colonized wheat roots (CWR).

Additional file 7: Figure S2. Scatter plot: RNA-seq vs. RT-qPCR. RNA-seq and RT-qPCR relative level of expression are presented as log2 (fold-change). Triticum aestivum genes presented in the scatter plot: TaS_37759224**, TaS_52545880**, contig_4027***, TaS_52541981*, TaS_22370925*, TaS_37846208*, TaS_17890143*, TaS_26026646*, TaS552541449** and contig_2766**. RNA-seq data represent biological duplicates of colonized and non-inoculated wheat roots. RT-qPCR data represent biological duplicates of colonized and non-inoculated wheat roots, obtained independently from the RNA-seq samples, and each sample was run in triplicate. Significant differences in the RT-qPCR $\left({ }^{*} p<0.05,{ }^{* *} p<0.01\right.$, and $\left.{ }^{* * *} p<0.001\right)$ were determined using one-tailed t-test. Pearson coefficient correlation between RNA-seq and RT-qPCR was $>0.97$, p-value $<0.0001$.

Additional file 8: Table S6. Triticum aestivum MADs-Box expressed-ESTs. ${ }^{a}$ Fold-change in red indicates lower level of expression in colonized wheat roots (CWR).

Additional file 9: Table S7. Expressed ORFs of Azospirillum brasilense strain FP2 colonizing Triticum aetivum seedling roots.

Additional file 10: Table S8. Host response found during plant-microbe interaction: Defense mechanism, hormone imbalances and secretion of

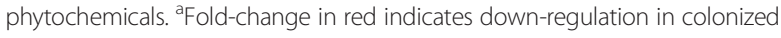
wheat roots (CWR); (+) ND not expressed in the N-IWR libraries; (-) ND not expressed in the CWR libraries.

Additional file 11: Table S9. ESTs of Triticum aestivum encoding transporters. ${ }^{2}$ Fold-change in red indicates lower level of expression in colonized wheat roots (CWR); (+) ND not expressed in the N-IWR libraries; Up-regulated, Down-regulated and Expressed ESTs are shading in red, blue and yellow respectively.

Additional file 12: Table S10. ESTs of Triticum aestivum encoding proteins that were grouped in transport activity by $\mathrm{GO}$ analysis. ${ }^{a}$ Fold-change in red indicates lower level of expression in colonized wheat roots (CWR); (+) ND not expressed in the N-IWR libraries; Up-regulated, Down-regulated and Expressed ESTs are shading in red, blue and yellow respectively.

Additional file 13: Table S11. ESTs of Triticum aestivum encoding proteins related to cell cycle regulation. ${ }^{a}$ Fold-change in red indicates down-regulation in colonized wheat roots (CWR).

\section{Competing interests}

The authors declare that they have no competing interests.

\section{Authors' contributions}

Conceived and designed the experiments: DC-N and EMS. Performed the experiments: DC-N, PB, MZT-S, LCCB-S, GV, LD, HF and VAW. Analyzed the 
data: DC-N, FOP, RW, LSC, PB and EMS. Wrote the paper: DC-N and EMS. All authors read and approved the final manuscript.

\section{Acknowledgements}

This work was supported by the Brazilian Program of National Institutes of Science and Technology-INCT/Brazilian Research Council-CNPq/MCT, CNPq (Conselho Nacional de Desenvolvimento Científico e Tecnológico), Fundação Araucária, and CAPES (Coordenação de Aperfeiçoamento de Pessoal de Nível Superior). We wish to thank Marshall G. Yates for comments on the manuscript and Leonardo M. Cruz and Rodrigo A. Cardoso for bioinformatics support. We are also thankful to Roseli A. Prado, Valter A. Baura and Marilza D. Lamour for technical assistance.

\section{Author details}

'Department of Biochemistry and Molecular Biology, Universidade Federal do Paraná, Curitiba, PR 81531-990, Brazil. ${ }^{2}$ Department of Genetics, Universidade Federal do Paraná, Curitiba, PR, Brazil. ${ }^{3}$ Department of Cellular Biology, Universidade Federal do Paraná, Curitiba, PR, Brazil. ${ }^{4}$ Departament of Biochemistry and Biotechnology, Universidade Estadual de Londrina, Londrina, PR, Brazil.

Received: 15 November 2013 Accepted: 2 May 2014

Published: 16 May 2014

\section{References}

1. Tester $\mathrm{M}$, Langridge $\mathrm{P}$ : Breeding technologies to increase crop production in a changing world. Science 2010, 327(5967):818-822.

2. Robertson GP, Vitousek PM: Nitrogen in agriculture: balancing the cost of an essential resource. Annu Rev Environ Resour 2009, 34:97-125.

3. Hirel B, Tétu T, Lea P, Dubois F: Improving nitrogen use efficiency in crops for sustainable agriculture. Sustainability 2011, 3(9):1452-1485.

4. Tilman D, Cassman KG, Matson PA, Naylor R, Polasky S: Agricultural sustainability and intensive production practices. Nature 2002 418(6898):671-677.

5. Hungria M, Campo RJ, Souza EM, Pedrosa FO: Inoculation with selected strains of azospirillum brasilense and A. lipoferum improves yields of maize and wheat in Brazil. Plant Soil 2010, 331(1-2):413-425.

6. Fibach-Paldi S, Burdman S, Okon Y: Key physiological properties contributing to rhizosphere adaptation and plant growth promotion abilities of azospirillum brasilense. FEMS Microbiol Lett 2012, 326(2):99-108.

7. Paux E, Sourdille P, Salse J, Saintenac C, Choulet F, Leroy P, Korol A, Michalak M, Kianian S, Spielmeyer W, Lagudah E, Somers D, Kilian A, Alaux M, Vautrin S, Berges H, Eversole K, Appels R, Safar J, Simkova H, Dolezel J, Bernard M, Feuillet $C$ : A physical map of the 1-gigabase bread wheat chromosome 3B. Science 2008, 322(5898):101.

8. Singh RP, Hodson DP, Huerta-Espino J, Jin Y, Bhavani S, Njau P, Herrera-Foessel S, Singh PK, Singh S, Govindan V: The emergence of Ug99 races of the stem rust fungus is a threat to world wheat production. Annu Rev Phytopathol 2011, 49:465-481.

9. Westermann AJ, Gorski SA, Vogel J: Dual RNA-seq of pathogen and host. Nat Rev Microbiol 2012, 10(9):618-630.

10. Kawahara $\mathrm{Y}$, Oono $\mathrm{Y}$, Kanamori $\mathrm{H}$, Matsumoto $\mathrm{T}$, Itoh T, Minami E: Simultaneous RNA-Seq analysis of a mixed transcriptome of rice and blast fungus interaction. Plos One 2012, 7(11):e49423.

11. Steenhoudt $\mathrm{O}$, Vanderleyden J: Azospirillum, a free-living nitrogen-fixing bacterium closely associated with grasses: genetic, biochemical and ecological aspects. FEMS Microbiol Rev 2000, 24(4):487-506

12. Okon Y: Azospirillum as a potential inoculant for agriculture. Trends Biotechnol 1985, 3(9):223-228.

13. Pinheiro RD, Boddey LH, James EK, Sprent Jl, Boddey RM: Adsorption and anchoring of azospirillum strains to roots of wheat seedlings. Plant Soil 2002, 246(2):151-166.

14. Kadouri $D$, Jurkevitch $E$, Okon $Y$ : Involvement of the reserve material poly-beta-hydroxybutyrate in azospirillum brasilense stress endurance and root colonization. Appl Environ Microbiol 2003, 69(6):3244-3250.

15. Zhang Z, Yu J, Li D, Liu F, Zhou X, Wang T, Ling Y, Su Z: PMRD: plant microRNA database. Nucleic Acids Res 2010, 38(Database issue):D806-D813.

16. Wisniewski-Dye F, Borziak K, Khalsa-Moyers G, Alexandre G, Sukharnikov LO, Wuichet K, Hurst GB, McDonald WH, Robertson JS, Barbe V, Calteau A, Rouy Z, Mangenot S, Prigent-Combaret C, Normand P, Boyer M, Siguier P, Dessaux Y, Elmerich C, Condemine G, Krishnen G, Kennedy I, Paterson AH,
Gonzalez V, Mavingui P, Zhulin IB: Azospirillum genomes reveal transition of bacteria from aquatic to terrestrial environments. PLOS Genet 2011, 7(12):e1002430.

17. Yao Y, Guo G, Ni Z, Sunkar R, Du J, Zhu J-K, Sun Q: Cloning and characterization of microRNAs from wheat (Triticum aestivum L.). Genome Biol 2007, 8(6):R96.

18. Sunkar R, Girke T, Jain PK, Zhu JK: Cloning and characterization of MicroRNAs from rice. Plant Cell 2005, 17(5):1397-1411.

19. Gutierrez RA: Systems biology for enhanced plant nitrogen nutrition. Science 2012, 336(6089):1673-1675.

20. Zhang HM, Forde BG: An arabidopsis MADS box gene that controls nutrient-induced changes in root architecture. Science 1998, 279(5349):407-409.

21. Vanbastelaere E, Demot R, Michiels $K$, Vanderleyden J: Differential geneexpression in Azospirillum spp by plant-root exudates - analysis of protein profiles by 2-dimensional polyacrylamide-gel electrophoresis. FEMS Microbiol Lett 1993, 112(3):335-342.

22. Van Bastelaere $E$, Lambrecht $M$, Vermeiren $H$, Van Dommelen $A$, Keijers $V$, Proost $\mathrm{P}$, Vanderleyden J: Characterization of a sugar-binding protein from azospirillum brasilense mediating chemotaxis to and uptake of sugars. Mol Microbiol 1999, 32(4):703-714

23. Ampe F, Kiss E, Sabourdy F, Batut J: Transcriptome analysis of sinorhizobium meliloti during symbiosis. Genome Biol 2003, 4(2):R15.

24. Moreno-Vivián C, Cabello P, Martínez-Luque M, Blasco R, Castillo F: Prokaryotic nitrate reduction: molecular properties and functional distinction among bacterial nitrate reductases. J Bacteriol 1999, 181(21):6573-6584

25. Van Alst NE, Picardo KF, Iglewski BH, Haidaris CG: Nitrate sensing and metabolism modulate motility, biofilm formation, and virulence in pseudomonas aeruginosa. Infect Immun 2007, 75(8):3780-3790.

26. Döbereiner J, Pedrosa FO: Nitrogen-fixing bacteria in nonleguminous crop plants. Berlin: Madison: Wl:Science Tech. Publishers; 1987.

27. James EK: Nitrogen fixation in endophytic and associative symbiosis. Field Crop Res 2000, 65(2-3):197-209.

28. Arsene F, Katupitiya S, Kennedy IR, Elmerich C: Use of lacz fusions to study the expression of nif genes of azospirillum-brasilense in association with plants. Mol Plant Microbe In 1994, 7(6):748-757.

29. Bari $R$, Jones JDG: Role of plant hormones in plant defence responses. Plant Mol Biol 2009, 69(4):473-488.

30. Robert-Seilaniantz A, Grant M, Jones JD: Hormone crosstalk in plant disease and defense: more than just jasmonate-salicylate antagonism. Annu Rev Phytopathol 2011, 49:317-343.

31. Elmore JM, Lin Z-JD, Coaker G: Plant NB-LRR signaling: upstreams and downstreams. Curr Opin Plant Biol 2011, 14(4):365-371.

32. Lee J-H, Yun HS, Kwon C: Molecular communications between plant heat shock responses and disease resistance. Mol Cells 2012, 34(2):109-116.

33. Broekaert WF, Delaure SL, De Bolle MFC, Cammuel BPA: The role of ethylene in host-pathoven interactions. Annu Rev Phytopathol 2006, 44:393-416.

34. Rubin G, Tohge T, Matsuda F, Saito K, Scheible WR: Members of the LBD family of transcription factors repress anthocyanin synthesis and affect additional nitrogen responses in arabidopsis. Plant Cell 2009, 21(11):3567-3584.

35. Lea US, Slimestad R, Smedvig P, Lillo C: Nitrogen deficiency enhances expression of specific MYB and bHLH transcription factors and accumulation of end products in the flavonoid pathway. Planta 2007, 225(5):1245-1253.

36. Nogueira ED, Olivares FL, Japiassu JC, Vilar C, Vinagre F, Baldani II, Hemerly AS: Characterization of glutamine synthetase genes in sugarcane genotypes with different rates of biological nitrogen fixation. Plant $\mathrm{SCi}$ 2005, 169(5):819-832.

37. Yang Z, Bruno DP, Martens CA, Porcella SF, Moss B: Simultaneous highresolution analysis of vaccinia virus and host cell transcriptomes by deep RNA sequencing. Proc Natl Acad Sci U S A 2010, 107(25):11513-11518.

38. Tierney L, Linde J, Mueller S, Brunke S, Molina JC, Hube B, Schoeck U, Guthke R, Kuchler K: An interspecies network inference model of candida albicans invading innate immune cells identifies novel host-pathogen interactions. Mycoses 2012, 55:57.

39. Schreiber AW, Hayden MJ, Forrest KL, Kong SL, Langridge P, Baumann U: Transcriptome-scale homoeolog-specific transcript assemblies of bread wheat. BMC Genomics 2012, 13:492. 
40. Duan J, Xia C, Zhao G, Jia J, Kong X: Optimizing de novo common wheat transcriptome assembly using short-read RNA-Seq data. BMC Genomics 2012, 13:392.

41. Lai K, Duran C, Berkman PJ, Lorenc MT, Stiller J, Manoli S, Hayden MJ, Forrest KL, Fleury D, Baumann U, Zander M, Mason AS, Batley J, Edwards D: Single nucleotide polymorphism discovery from wheat next-generation sequence data. Plant Biotechnol J 2012, 10(6):743-749.

42. Cantu D, Pearce SP, Distelfeld A, Christiansen MW, Uauy C, Akhunov E, Fahima T, Dubcovsky J: Effect of the down-regulation of the high grain protein content (GPC) genes on the wheat transcriptome during monocarpic senescence. BMC Genomics 2011, 12:492.

43. Pont C, Murat F, Confolent C, Balzergue S, Salse J: RNA-seq in grain unveils fate of neo- and paleopolyploidization events in bread wheat (Triticum aestivum L.). Genome Biol 2011, 12(12):R119.

44. Gillies SA, Futardo A, Henry RJ: Gene expression in the developing aleurone and starchy endosperm of wheat. Plant Biotechnol J 2012, 10(6):668-679.

45. Pellny TK, Lovegrove A, Freeman J, Tosi P, Love CG, Knox JP, Shewry PR, Mitchell RAC: Cell walls of developing wheat starchy endosperm: comparison of composition and RNA-Seq transcriptome. Plant Physiol 2012, 158(2):612-627.

46. Trick M, Adamski NM, Mugford SG, Jiang C-C, Febrer M, Uauy C: Combining SNP discovery from next-generation sequencing data with bulked segregant analysis (BSA) to fine-map genes in polyploid wheat. BMC Plant Biol 2012, 12:14

47. Li A, Zhang R, Pan L, Tang L, Zhao G, Zhu M, Chu J, Sun X, Wei B, Zhang X, Jia J, Mao L: Transcriptome analysis of $\mathrm{H} 2 \mathrm{O} 2$-treated wheat seedlings reveals a $\mathrm{H} 2 \mathrm{O} 2$-responsive fatty acid desaturase gene participating in powdery mildew resistance. Plos One 2011, 6(12):e28810

48. Segonzac C, Boyer J-C, Ipotesi E, Szponarski W, Tillard P, Touraine B, Sommerer N, Rossignol M, Gibrat R: Nitrate efflux at the root plasma membrane: identification of an arabidopsis excretion transporter. Plant Cell 2007, 19(11):3760-3777.

49. Wendehenne D, Lamotte O, Frachisse JM, Barbier-Brygoo H, Pugin A: Nitrate efflux is an essential component of the cryptogein signaling pathway leading to defense responses and hypersensitive cell death in tobacco. Plant Cell 2002, 14(8):1937-1951.

50. Oldroyd GED, Harrison MJ, Paszkowski U: Reprogramming plant cells for endosymbiosis. Science 2009, 324(5928):753-754.

51. Bednarek P, Kwon C, Schulze-Lefert P: Not a peripheral issue: secretion in plant-microbe interactions. Curr Opin Plant Biol 2010, 13(4):378-387.

52. Zhang J, Subramanian S, Stacey G, Yu O: Flavones and flavonols play distinct critical roles during nodulation of medicago truncatula by sinorhizobium meliloti. Plant J 2009, 57(1):171-183.

53. Robert-Seilaniantz A, Navarro L, Bari R, Jones JD: Pathological hormone imbalances. Curr Opin Plant Biol 2007, 10(4):372-379.

54. Spoel SH, Dong X: Making sense of hormone crosstalk during plant immune responses. Cell Host Microbe 2008, 3(6):348-351.

55. Sziderics AH, Rasche F, Trognitz F, Sessitsch A, Wilhelm E: Bacterial endophytes contribute to abiotic stress adaptation in pepper plants (Capsicum annuum L.). Can J Microbiol 2007, 53(11):1195-1202.

56. Dimkpa C, Weinand T, Asch F: Plant-rhizobacteria interactions alleviate abiotic stress conditions. Plant Cell Environ 2009, 32(12):1682-1694.

57. Varin L, Deluca V, Ibrahim RK, Brisson N: Molecular characterization of 2 plant flavonol sulfotransferases. Proc Natl Acad Sci U S A 1992, 89(4):1286-1290.

58. Barassi CA, Ayrault G, Creus CM, Sueldo RJ, Sobrero MT: Seed inoculation with azospirillum mitigates $\mathrm{NaCl}$ effects on lettuce. Sci Hortic 2006, 109(1):8-14

59. Creus CM, Sueldo RJ, Barassi CA: Water relations and yield in azospirilluminoculated wheat exposed to drought in the field. Can J Bot 2004, 82(2):273-281

60. Pereyra MA, Zalazar CA, Barassi CA: Root phospholipids in azospirilluminoculated wheat seedlings exposed to water stress. Plant Physiol Biochem 2006, 44(11-12):873-879.

61. Pereyra MA, Garcia P, Colabelli MN, Barassi CA, Creus CM: A better water status in wheat seedlings induced by azospirillum under osmotic stress is related to morphological changes in xylem vessels of the coleoptile. App/ Soil Ecol 2012, 53:94-97.

62. Cassan F, Maiale S, Masciarelli O, Vidal A, Luna V, Ruiz O: Cadaverine production by azospirillum brasilense and its possible role in plant growth promotion and osmotic stress mitigation. Eur J Soil Biol 2009, 45(1):12-19.

63. Hamaoui B, Abbadi JM, Burdman S, Rashid A, Sarig S, Okon Y: Effects of inoculation with azospirillum brasilense on chickpeas (Cicer arietinum) and faba beans (Vicia faba) under different growth conditions. Agronomie 2001, 21(6-7):553-560.

64. Hamdia ABE, Shaddad MAK, Doaa MM: Mechanisms of salt tolerance and interactive effects of azospirillum brasilense inoculation on maize cultivars grown under salt stress conditions. Plant Growth Regul 2004, 44(2):165-174.

65. Hoagland D, Arnon D: The water-culture method for growing plants without soil. Circular California Agriculture Experimental Station 1950, 347:1-32

66. Machado HB, Funayama S, Rigo LU, Pedrosa FQ: Excretion of ammonium by azospirillum-brasilense mutants resistant to ethylenediamine. Can J Microbiol 1991, 37(7):549-553.

67. Galbraith DW, Harkins KR, Maddox JM, Ayres NM, Sharma DP, Firoozabady E: Rapid flow cytometric analysis of the cell-cycle in intact plant-tissues. Science 1983, 220(4601):1049-1051.

68. Karnovsk M: A formaldehyde-glutaraldehyde fixative of high osmolality for use in electron microscopy. J Cell Biol 1965, 27(2):A137.

69. Luft JH: Improvements in epoxy resin embedding methods. J Biophys Biochem Cytol 1961, 9(2):409.

70. Watson ML: Staining of tissue sections for electron microscopy with heavy metals. J Biophys Biochem Cytol 1958, 4(4):475.

71. Reynolds ES: The use of lead citrate at high $\mathrm{pH}$ as an electron-opaque stain in electron microscopy. J Cell Biol 1963, 17(1):208.

72. Anders S, Huber W: Differential expression analysis for sequence count data. Genome Biol 2010, 11(10):R106

73. Conesa A, Gotz S, Garcia-Gomez JM, Terol J, Talon M, Robles M: Blast2GO: a universal tool for annotation, visualization and analysis in functional genomics research. Bioinformatics 2005, 21(18):3674-3676.

74. Pfaffl MW: A new mathematical model for relative quantification in real-time RT-PCR. Nucleic Acids Res 2001, 29(9):e45.

75. Vandesompele J, De Preter K, Pattyn F, Poppe B, Van Roy N, De Paepe A, Speleman F: Accurate normalization of real-time quantitative RT-PCR data by geometric averaging of multiple internal control genes. Genome Biol 2002, 3(7):RESEARCH0034.

\section{doi:10.1186/1471-2164-15-378}

Cite this article as: Camilios-Neto et al:: Dual RNA-seq transcriptional analysis of wheat roots colonized by Azospirillum brasilense reveals up-regulation of nutrient acquisition and cell cycle genes. BMC Genomics 2014 15:378.

\section{Submit your next manuscript to BioMed Central and take full advantage of:}

- Convenient online submission

- Thorough peer review

- No space constraints or color figure charges

- Immediate publication on acceptance

- Inclusion in PubMed, CAS, Scopus and Google Scholar

- Research which is freely available for redistribution 